\title{
Ambient temperature as trigger of preterm delivery in a temperate climate
}

Bianca $\operatorname{Cox}^{1}$, Ana M Vicedo-Cabrera ${ }^{2}$, Antonio Gasparrini ${ }^{3,4}$, Harry A Roels ${ }^{1,5}$, Evelyne Martens $^{6}$, Jaco Vangronsveld ${ }^{1}$, Bertil Forsberg ${ }^{2}$, Tim S Nawrot ${ }^{1,7}$

\section{Author affiliations:}

1. Centre for Environmental Sciences, Hasselt University, Diepenbeek, Belgium

2. Occupational and Environmental Medicine, Department of Public Health and Clinical Medicine, Umeå University, Umeå, Sweden

3. Department of Social and Environmental Health Research, London School of Hygiene and Tropical Medicine (LSHTM), London, United Kingdom

4. Department of Medical Statistics, LSHTM, London, United Kingdom

5. Louvain Centre for Toxicology and Applied Pharmacology, Université catholique de Louvain, Brussels, Belgium

6. Study Centre for Perinatal Epidemiology, Brussels, Belgium

7. Department of Public Health and Primary Care, Leuven University, Leuven, Belgium

\section{Corresponding author:}

Dr Tim S. Nawrot, associate professor of environmental epidemiology, Centre for Environmental Sciences, Hasselt University, Agoralaan building D, 3590 Diepenbeek, Belgium. Telephone: 32-11-268382. Fax: 32-11-268299. E-mail: tim.nawrot@uhasselt.be

\section{Keywords:}

Cold, DLNM, Heat, Preterm birth, Temperature

\section{Word count:}




\section{ABSTRACT}

Background Recent evidence suggests that elevated ambient temperatures may trigger preterm delivery. Because results from studies in temperate climates are inconclusive, we investigated the association between temperature and the risk of preterm birth in Flanders (Belgium).

Methods We used data on 807,835 singleton deliveries (January 1998 - July 2011). We combined a quasi-Poisson model with distributed lag non-linear models to allow for delayed and non-linear temperature effects, accounting for the daily pregnancies at risk and their gestational age distribution.

Results For moderate heat (95th $v s$. 50th percentile) up to 1 day before delivery (lag $0-1)$, the risk of preterm birth increased by $8.5 \%$ (95\% CI $2.4 \%$ to $15.0 \%$ ) when minimum temperature increased from $8.3^{\circ}$ to $16.3^{\circ} \mathrm{C}$ and by $9.6 \%$ (95\% CI $1.1 \%$ to $18.7 \%$ ) when maximum temperature increased from $14.7^{\circ} \mathrm{C}$ to $26.5^{\circ} \mathrm{C}$. Corresponding estimates for extreme heat (99th vs. 50th percentile) were $15.6 \%$ (95\% CI $4.8 \%$ to $27.6 \%)$ for minimum temperature $\left(19.0^{\circ} \mathrm{C} v s\right.$. $\left.8.3^{\circ} \mathrm{C}\right)$ and $14.5 \%(95 \% \mathrm{CI} 0.5 \%$ to $30.6 \%)$ for maximum temperature $\left(30.7^{\circ} \mathrm{C} v s .14 .7^{\circ} \mathrm{C}\right)$. Despite the increased risk of preterm birth associated with cold at lag 2 (and lag 1 for minimum temperature), cumulative cold effects were small. The percent change in preterm birth associated with moderate cold (5th $v s$. 50th percentile) up to 3 days before delivery (lag 0-3) was $2.1 \%(95 \% \mathrm{CI}-4.1 \%$ to $8.7 \%)$ for minimum temperature $\left(-2.0^{\circ} \mathrm{C} v s .8 .3^{\circ} \mathrm{C}\right)$ and $0.6 \%(95 \%$ CI $-7.3 \%$ to $9.2 \%)$ for maximum temperature $\left(2.5^{\circ} \mathrm{C} v s .14 .7^{\circ} \mathrm{C}\right)$.

Conclusions Even in a temperate climate, ambient temperature may trigger preterm delivery, suggesting that pregnant women should avoid temperature extremes. 


\section{BACKGROUND}

Preterm delivery is the primary cause of perinatal morbidity and mortality in developed countries.[1] While adverse health outcomes are most obvious for lower gestational ages, even late preterm births (34-36 weeks) have higher morbidity and mortality rates than full-term births.[2] Because many of these effects continue into childhood and even adulthood,[2] preterm birth is a serious public health issue with major economic implications.[3]

Despite extensive research and clinical efforts designed toward the reduction of preterm delivery, rates continue to rise in most regions.[1, 4] In 2010, the mean preterm birth rate in developed regions was $8.6 \%$, and in the US it has increased from $10.6 \%$ to $12.0 \%$ during the last two decades.[4] The underlying causes of preterm birth are poorly understood, although genetic, demographic, social-behavioural, and environmental factors are likely to play a role.[1, 5]

Recent evidence, mainly from studies in warm climates, suggests that elevated ambient temperatures may trigger preterm delivery.[6,7] Among the few studies conducted in temperate climates,[8-12] an association between temperature and preterm birth has only been found in Sweden.[11, 12] Moreover, although studies on seasonality of birth outcomes have reported peaks of preterm birth not only in summer but also in winter,[13] only a limited number of studies investigated short-term effects of cold.[8, 9, 11, 12, 14-16]

We studied the association between ambient temperature and the risk of preterm birth in the temperate climate of Flanders (Belgium). We investigated the impact of both heat and cold and we considered the possibility of non-linear and lagged exposure effects. 


\section{METHODS}

\section{Data}

The Study Centre for Perinatal Epidemiology (SPE) supplied information on births in Flanders during the period 1998-2011. Flanders is the Northern part of Belgium and is predominantly Dutch-speaking, with about six million inhabitants and 68 fully equipped maternity-obstetric units where $99.8 \%$ of all births occur.[17] For each newborn of at least $500 \mathrm{~g}$, an official and coded perinatal form is completed (most often by the midwife) and sent to the SPE, where all data are controlled by an error detection programme.[18] An assessment of the quality of SPE data shows that there is less than $5 \%$ discrepancy between electronic data and data out of medical files.[19] Gestational age is based on the last menstrual period and is corrected according to the estimation from the first ultrasound.

We limited our study population to live-born singleton births with a gestational age between 22 and 42 weeks. Preterm births were classified as follows: <32 weeks (extremely to very preterm) and 32-36 weeks (moderate to late preterm) (World Health Organization, http://www.who.int/mediacentre/factsheets/fs363/en/). For births from 1999 to 2009, information on maternal education was available through linkage of the medical birth certificates of the SPE with official birth declarations.

Data on daily minimum and maximum air temperature and relative humidity, measured at the representative station in Uccle (Brussels), were provided by the Belgian Royal Meteorological Institute. As air pollution may confound the association between temperature and preterm birth,[20,21] data on daily concentrations of particulate matter with diameter less than $10 \mu \mathrm{m}$ ( $\mathrm{PM}_{10}$, daily average $)$ and ozone $\left(\mathrm{O}_{3}, 8\right.$-hour maximum) were obtained from the Belgian Interregional Environment Agency. Flanders has a dense network of automatic monitoring sites, collecting real-time data on a half-hourly basis. The average distance between the nearest 
measuring stations is about $25 \mathrm{~km}$. Data from monitoring stations are combined with land cover data obtained from satellite images in a spatial-temporal (Kriging) interpolation model, described by Janssen et al.[22] This provides air pollutant concentrations on a $4 \times \mathrm{xm}^{2}$ grid, which are then used to calculate population-weighted average daily concentrations for Flanders.

Higher preterm birth rates in winter have been linked to a higher prevalence of influenza, as influenza infections may trigger preterm delivery, potentially through inflammation.[23] To adjust for the potential confounding effect of influenza episodes, we obtained data on weekly consultation rates for influenza-like illnesses from the representative Belgian Sentinel General Practitioner network, coordinated by the WIV-ISP (Scientific Institute of Public Health).[24] Influenza epidemics were defined as weeks (from Monday to Sunday) with an incidence above the threshold of 141 cases per 100,000 inhabitants.[24]

The research protocol was approved by the medical ethics committee of Hasselt University.

\section{Statistical analysis}

Daily counts of preterm births were modelled by combining quasi-Poisson regression with distributed lag non-linear models (DLNM).[25] This approach allows simultaneous estimation of the non-linear exposure-response association and the non-linear effects across lags, the latter termed lag-response association. We used the following model for minimum and maximum temperature:

$Y_{t} \sim \operatorname{Poisson}\left(\mu_{t}\right)$

$\log \left(\frac{\mu_{t}}{Z_{t}}\right)=\alpha+\boldsymbol{\beta} \boldsymbol{T}_{t, l}+S(R H, 3)+S\left(P M_{10}, 3\right)+S\left(O_{3}, 3\right)+S($ time, $6 /$ year $)+\gamma \mathrm{DOW}_{t}+\delta$ Holiday $_{t}$

$+\lambda \operatorname{Influenza}_{t}+S\left(\log \left(W_{t}\right), 4\right)$ 
where $Y_{t}$ is the observed number of preterm births and $Z_{t}$ the number of pregnancies at risk on day $t ; \alpha$ is the intercept; $\boldsymbol{T}_{t, l}$ is a matrix representing the two-dimensional DLNM cross-basis for temperature and lag days, $\boldsymbol{\beta}$ is vector of coefficients for $\boldsymbol{T}_{t, l}$, and $l$ is the lag days. $S(R H, 3)$, $S\left(P M_{10}, 3\right)$, and $S\left(O_{3}, 3\right)$ are natural cubic splines with 3 degrees of freedom (df) for relative humidity, $\mathrm{PM}_{10}$, and $\mathrm{O}_{3}$, respectively, using the average exposure of the current day and the previous for each of these variables. Long-term trends[26] and seasonality were modelled using a natural cubic spline of time with 6 df per year. $\mathrm{DOW}_{t}$ is a categorical variable for day of the week, and $\gamma$ is vector of coefficients. Holiday $t$ is a binary variable that is " 1 " if day $t$ was a public holiday, and $\delta$ is the coefficient. Influenza $t$ is a binary variable that is " 1 " if day $t$ was inside an epidemic influenza week, and $\lambda$ is the coefficient. $S\left(\log \left(W_{t}\right), 4\right)$ is a natural cubic spline with 4 df with:

$W_{t}=\frac{\sum_{j=22}^{36}\left(Z_{t j} * W_{j}\right)}{Z_{t}}$

where $Z_{t j}$ is the number of pregnancies at risk during gestational week $j$ (ranging from 22 through 36 weeks) on day $t$, and $W_{j}$ is the conditional probability of birth during gestational week $j$, as proposed by Vicedo-Cabrera et al[27] to account for the temporal variation in the number of pregnancies at risk of preterm birth and their gestational age distribution. This approach was used because, as demonstrated by Darrow et al[28], seasonality in the underlying risk of preterm birth could confound time-series studies examining a seasonally-varying exposure. Induced deliveries and caesarean sections were excluded from $\mu_{t}$ because they are less likely to be related to external factors such as temperature, but they were included in the calculation of $Z_{t}$ and $W_{t}$ because they are at risk of preterm birth until the date of induction or caesarean section. As pregnancies with birth dates after the end of the study period do not appear in the at risk set, the denominator is decreasing at the end of the dataset. Therefore, the last 5 months of the study period (August-December 2011) were excluded from the analysis. 
We used a DLNM that modelled both the nonlinear temperature effect and the lagged effect using a natural cubic spline. The maximum lag was set at 6 days. Lag 0 was defined as the 24hour period from midnight to midnight, of the day of the birth, and lag 1 as the preceding 24hour period, and so on. Spline knots were placed at equal spaces in the temperature range, whereas knots in the lag space were set at equally spaced values on the log scale of lags.[29] The df were selected according to the Akaike information criterion for quasi-Poisson models,[25] varying the df for the exposure-response from 2 to 6 and for the lag-response from 3 to 6 . The final model for minimum temperature contained $3 \mathrm{df}$ for temperature and $4 \mathrm{df}$ for the lag structure, whereas the final model for maximum temperature contained $2 \mathrm{df}$ for temperature and $5 \mathrm{df}$ for the lag structure. The estimated dispersion parameter was 0.97 in the model for minimum temperature and 0.98 in the model for maximum temperature. The median values of the temperature indicators were used as reference. Relative risks of preterm birth were calculated for moderate heat (95th percentile), extreme heat (99th percentile), moderate cold (5th percentile), and extreme cold (1st percentile). Cumulative effects over lag 0-1, lag 0-3, and lag 0-6 days were computed by summing the log relative risks over the lags.

In addition to the analysis for all (non-induced vaginal) preterm births, we conducted stratified analyses by gestational age ( $<32$ weeks, 32-36 weeks), gender, parity (first, higher), maternal age group ( $<25$ years, 25-34 years, $\geq 35$ years), maternal education (lower secondary or less, higher secondary, higher education) and the degree of urbanization of mother's residence (urban/semi-urban vs. rural).[30] Because temperature may also act as a trigger for labour among term births,[10] we additionally considered early-term (37-38 weeks) and full-term (>38 weeks) births in the stratified analysis. $Z_{t}$ and $W_{t}$ were recalculated for each of the subpopulations.

We did a sensitivity analysis to assess the impact of model choices. We increased the maximum lag to 8 and 10 days and we varied the df for temperature ( 2 to $6 \mathrm{df}$ ), for the lag structure ( 3 to 
$6 \mathrm{df}$ ), for the seasonal and long-term trend component (4 to $10 \mathrm{df}$ per year), and for $\log \left(W_{t}\right)(1$ to $6 \mathrm{df})$. We also explored the potential confounding by air pollution $\left(P M_{10}\right.$ and $\left.O_{3}\right)$ and by the pregnancies at risk $\left(Z_{t}\right)$ and their gestational age distribution $\left(W_{t}\right)$ by excluding these variables from the model one at a time. Results from subpopulation and sensitivity analyses are presented as the cumulative heat effect over lag 0-1 days and the cumulative cold effect over lag 0-3 days. All analyses were performed with the statistical software R, using the "dlnm" package.[29]

\section{RESULTS}

\section{Data description}

There were 807,835 live-born singleton births in Flanders from January 1998 until July 2011, including 467,502 (57.9\%) non-induced vaginal births (table 1). A total of 27,076 (5.8\%) from these non-induced vaginal births were preterm. The mean number of cases per day was 5.5 and the percentage of days without cases was less than $0.4 \%$. The majority of preterm births $(92.6 \%)$ had a gestational age from 32 to 36 weeks (moderate to late preterm). 
Table 1 Descriptive characteristics of the study population, Flanders, Belgium, January 1998 - July 2011

\begin{tabular}{|c|c|c|c|c|c|c|}
\hline \multirow[b]{3}{*}{ Characteristic } & \multicolumn{2}{|c|}{ All births ${ }^{a}$} & \multicolumn{4}{|c|}{ Non-induced vaginal births ${ }^{\text {b }}$} \\
\hline & \multicolumn{2}{|l|}{ All } & \multicolumn{2}{|l|}{ All } & \multicolumn{2}{|c|}{ Preterm } \\
\hline & No. & $\%$ & No. & $\%$ & No. & $\%$ \\
\hline Total & 807,835 & 100 & 467,502 & 100 & 27,076 & 100 \\
\hline \multicolumn{7}{|l|}{ Season } \\
\hline Spring (Mar-May) & 211,101 & 26.1 & 122,494 & 26.2 & 7,086 & 26.2 \\
\hline Summer (Jun-Aug) & 210,512 & 26.1 & 122,043 & 26.1 & 7,010 & 25.9 \\
\hline Autumn (Sep-Nov) & 190,029 & 23.5 & 109,550 & 23.4 & 6,159 & 22.8 \\
\hline Winter (Dec-Feb) & 196,193 & 24.3 & 113,415 & 24.3 & 6,821 & 25.2 \\
\hline \multicolumn{7}{|l|}{ Gestational age } \\
\hline$<32$ weeks & 5,099 & 0.6 & 2,005 & 0.4 & 2,005 & 7.4 \\
\hline 32-36 weeks & 43,166 & 5.3 & 25,071 & 5.4 & 25,071 & 92.6 \\
\hline 37-38 weeks & 201,222 & 24.9 & 106,091 & 22.7 & l & I \\
\hline$>38$ weeks & 558,348 & 69.1 & 334,335 & 71.5 & l & I \\
\hline \multicolumn{7}{|l|}{ Gender } \\
\hline Male & 414,898 & 51.4 & 239,976 & 51.3 & 15,160 & 56.0 \\
\hline Female & 392,937 & 48.6 & 227,526 & 48.7 & 11,916 & 44.0 \\
\hline \multicolumn{7}{|l|}{ Parity } \\
\hline First & 377,331 & 46.7 & 217,888 & 46.6 & 14,999 & 55.4 \\
\hline Higher & 430,504 & 53.3 & 249,614 & 53.4 & 12,077 & 44.6 \\
\hline \multicolumn{7}{|l|}{ Maternal age } \\
\hline$<25$ years & 134,225 & 16.6 & 79,559 & 17.0 & 5,687 & 21.0 \\
\hline $25-34$ years & 574,430 & 71.1 & 335,520 & 71.8 & 18,310 & 67.6 \\
\hline$\geq 35$ years & 99,180 & 12.3 & 52,423 & 11.2 & 3,079 & 11.4 \\
\hline \multicolumn{7}{|l|}{ Maternal education ${ }^{c}$} \\
\hline Low & 82,350 & 12.7 & 46,611 & 12.5 & 3,339 & 15.2 \\
\hline Medium & 251,334 & 38.8 & 137,427 & 36.8 & 9,145 & 41.7 \\
\hline High & 274,075 & 42.3 & 164,519 & 44.1 & 7,978 & 36.4 \\
\hline Missing data & 40,841 & 6.3 & 24,519 & 6.6 & 1,457 & 6.7 \\
\hline \multicolumn{7}{|l|}{ Urbanization } \\
\hline Urban & 609,440 & 75.4 & 352,857 & 75.5 & 20,486 & 75.7 \\
\hline Rural & 198,395 & 24.6 & 114,645 & 24.5 & 6,590 & 24.3 \\
\hline
\end{tabular}

${ }^{\text {a } U s e d ~ t o ~ c a l c u l a t e ~ t h e ~ d a i l y ~ n u m b e r ~ o f ~ p r e g n a n c i e s ~ a t ~ r i s k ~}\left(Z_{t}\right)$.

${ }^{\mathrm{b}}$ Used to calculate the daily number of preterm births $\left(\mu_{t}\right)$.

${ }^{\text {cFom }} 1999$ to 2009. 
Minimum temperature ranged from -12.3 to $23.9^{\circ} \mathrm{C}$, with a median of $8.3^{\circ} \mathrm{C}$. Maximum temperature ranged from -6.0 to $35.8^{\circ} \mathrm{C}$, with a median of $14.7^{\circ} \mathrm{C}$ (table 2). Relative humidity had a median (range) of $79.5 \%$ (32.1 to 99.9\%). The median (range) $\mathrm{PM}_{10}$ and $\mathrm{O}_{3}$ concentrations were $25.9 \mu \mathrm{g} / \mathrm{m}^{3}$ (5.2 to $\left.150.5 \mu \mathrm{g} / \mathrm{m}^{3}\right)$ and $45.4 \mu \mathrm{g} / \mathrm{m}^{3}\left(6.1\right.$ to $\left.129.9 \mu \mathrm{g} / \mathrm{m}^{3}\right)$, respectively.

Table 2 Distribution of the meteorological and air pollution variables, Flanders, Belgium, January 1998 - July 2011

\begin{tabular}{lrrrrrrr}
\hline & \multicolumn{7}{c}{ Percentiles } \\
Exposure & 0th & 1st & 5th & 50th & 95th & 99th & 100th \\
\hline Minimum temperature, ${ }^{\circ} \mathrm{C}$ & -12.3 & -5.6 & -2.0 & 8.3 & 16.3 & 19.0 & 23.9 \\
Maximum temperature, ${ }^{\circ} \mathrm{C}$ & -6.0 & -1.0 & 2.5 & 14.7 & 26.5 & 30.7 & 35.8 \\
Mean relative humidity, \% & 32.1 & 45.6 & 56.1 & 79.5 & 93.6 & 97.0 & 99.9 \\
$\mathrm{PM}_{10}, \mu \mathrm{g} / \mathrm{m}^{3}$ & 5.2 & 10.9 & 13.9 & 25.9 & 54.4 & 76.6 & 150.5 \\
$\mathrm{O}_{3}, \mu \mathrm{g} / \mathrm{m}^{3}$ & 6.1 & 7.5 & 11.6 & 45.4 & 77.9 & 95.5 & 129.9 \\
\hline
\end{tabular}

$\mathrm{PM}_{10}$, particulate matter with diameter less than $10 \mu \mathrm{m} ; \mathrm{O}_{3}$, ozone.

The Pearson correlation ( $r$ ) between minimum and maximum temperature was 0.90 (supplementary table S1). Humidity was more strongly correlated with maximum temperature $(\mathrm{r}=-0.52)$ than with minimum temperature $(\mathrm{r}=-0.27)$, whereas $\mathrm{PM}_{10}$ showed a higher correlation with minimum temperature $(r=-0.20)$ than with maximum temperature $(r=-0.05)$. Correlations with $\mathrm{O}_{3}$ were 0.52 for minimum temperature and 0.59 for maximum temperature.

\section{Main analysis}

For minimum temperature, the distributed non-linear lag surface showed a non-linear relationship with preterm birth at lags 0 to 2 , whereas the response was relatively flat at longer lags (figure 1A). The heat effect was highest at lag 0 and relative risks increased with increasing 
temperature. An effect of cold was observed at lags 1 and 2: relative risks were $>1$ for minimum temperatures roughly between the 50th percentile $\left(8.3^{\circ} \mathrm{C}\right)$ and the 5 th percentile $\left(-2.0^{\circ} \mathrm{C}\right)$, but not for lower temperatures. Maximum temperature effects were delayed by one day compared to minimum temperature effects, i.e. the heat effect appeared at lag 1 and the cold effect at lag 2 (figure 1B). For the heat effect as well as the cold effect, relative risks were highest at the most extreme temperatures.

Figure 2 presents the lag-specific relative risks of preterm birth for moderate heat (95th $v s$. 50th percentile, figure 2A) and for moderate cold (5th $v s$. 50th percentile, figure 2B). For minimum temperature, the heat effect was highest at lag $0(\mathrm{RR}=1.072 ; 95 \% \mathrm{CI} 1.015$ to 1.133$)$, and the cold effect was highest at lag $1(\mathrm{RR}=1.056 ; 95 \% \mathrm{CI} 1.006$ to 1.108). For maximum temperature, the heat effect was highest at lag $1(\mathrm{RR}=1.107 ; 95 \% \mathrm{CI} 1.024$ to 1.196$)$ and the cold effect at lag $2(\mathrm{RR}=1.069 ; 95 \% \mathrm{CI} 0.982$ to 1.163$)$. Note that relative risks for moderate cold at lag 0 were $<1$ for both temperature indicators (figure 2B).

Figure 3 presents the cumulative effect of temperature on preterm birth estimated over lag 0-1 days (A) and over lag 0-3 days (B). For minimum temperature, the cumulative heat effect over lag 0-3 days was larger than the heat effect over lag 0-1 days, whereas for maximum temperature, the lag 0-3 curve was relatively flat. Due to the seemingly protective effect of cold at lag 0 , cumulative relative risks were $<1$ (or close to 1 ) at low minimum and maximum temperatures.

Table 3 presents the cumulative relative risks of preterm birth associated with moderate heat (95th percentile), extreme heat (99th percentile), moderate cold (5th percentile), and extreme cold (1st percentile), relative to the median of the temperature distribution. The risk of preterm birth increased by $8.5 \%$ (95\% CI $2.4 \%$ to $15.0 \%$ ) when minimum temperature up to 1 day before delivery (lag 0-1) increased from $8.3^{\circ}$ to $16.3^{\circ} \mathrm{C}$ (moderate heat) and by $15.6 \%$ (95\% CI 
$4.8 \%$ to $27.6 \%$ ) when minimum temperature increased to $19.0^{\circ} \mathrm{C}$ (extreme heat). Corresponding estimates for maximum temperature were $9.6 \%$ (95\% CI $1.1 \%$ to $18.7 \%$ ) for an increase from $14.7^{\circ} \mathrm{C}$ to $26.5^{\circ} \mathrm{C}$ (moderate heat) and $14.5 \%$ (95\% CI $0.5 \%$ to $30.6 \%$ ) for an increase to $30.7^{\circ} \mathrm{C}$ (extreme heat). Despite the increased risk of preterm birth associated with cold at lag 2 (and lag 1 for minimum temperature), cumulative relative risks for moderate and extreme cold were close to one. For minimum temperature up to 3 days before delivery (lag $0-3$ ), the percent change in preterm birth associated with moderate cold $\left(-2.0^{\circ} \mathrm{C} v s .8 .3^{\circ} \mathrm{C}\right)$ was $2.1 \%(95 \% \mathrm{CI}-$ $4.1 \%$ to $8.7 \%)$. The corresponding estimate for maximum temperature $\left(2.5^{\circ} \mathrm{C} v s .14 .7^{\circ} \mathrm{C}\right)$ was $0.6 \%(95 \%$ CI $-7.3 \%$ to $9.2 \%)$. 
Table 3 Cumulative heat and cold effects of minimum temperature (Tmin) and maximum temperature (Tmax) on preterm birth in Flanders,

Belgium, January 1998 - July 2011

\begin{tabular}{|c|c|c|c|c|c|c|c|c|}
\hline \multirow[b]{3}{*}{ Lag, day } & \multicolumn{8}{|c|}{ Relative risk $(95 \% \mathrm{CI})^{\mathrm{a}}$} \\
\hline & \multicolumn{4}{|c|}{ Moderate heat } & \multicolumn{4}{|c|}{ Extreme heat } \\
\hline & \multicolumn{2}{|c|}{ Tmin } & \multicolumn{2}{|l|}{ Tmax } & \multicolumn{2}{|c|}{ Tmin } & \multicolumn{2}{|l|}{ Tmax } \\
\hline $0-1$ & 1.085 & (1.024 to 1.150$)$ & 1.096 & (1.011 to 1.187$)$ & 1.156 & (1.048 to 1.276$)$ & 1.145 & (1.005 to 1.306$)$ \\
\hline $0-3$ & 1.103 & (1.034 to 1.176$)$ & 1.027 & (0.947 to 1.113$)$ & 1.217 & (1.091 to 1.358$)$ & 1.046 & (0.915 to 1.194$)$ \\
\hline \multirow[t]{2}{*}{$0-6$} & 1.088 & $(1.007$ to 1.175$)$ & 1.091 & $(0.997$ to 1.192$)$ & 1.192 & $(1.045$ to 1.359$)$ & 1.146 & (0.990 to 1.328$)$ \\
\hline & \multicolumn{4}{|c|}{ Moderate cold } & \multicolumn{4}{|c|}{ Extreme cold } \\
\hline Lag, day & \multicolumn{2}{|c|}{ Tmin } & \multicolumn{2}{|l|}{ Tmax } & \multicolumn{2}{|c|}{ Tmin } & \multicolumn{2}{|l|}{ Tmax } \\
\hline $0-1$ & 0.973 & (0.918 to 1.031$)$ & 0.921 & (0.842 to 1.008$)$ & 0.930 & (0.842 to 1.028$)$ & 0.906 & (0.803 to 1.021$)$ \\
\hline $0-3$ & 1.021 & (0.959 to 1.087$)$ & 1.006 & $(0.927$ to 1.092$)$ & 0.961 & (0.865 to 1.067$)$ & 1.011 & (0.906 to 1.127$)$ \\
\hline $0-6$ & 0.998 & $(0.928$ to 1.074$)$ & 0.965 & $(0.884$ to 1.053$)$ & 0.910 & (0.804 to 1.029$)$ & 0.963 & (0.857 to 1.081$)$ \\
\hline
\end{tabular}

Moderate heat, extreme heat, moderate cold, and extreme cold were defined as the 95 th (Tmin: $16.3^{\circ} \mathrm{C}$; Tmax: $\left.26.5^{\circ} \mathrm{C}\right), 99 \mathrm{th}\left(\mathrm{Tmin}: 19.0^{\circ} \mathrm{C}\right.$; Tmax: 30.7$), 5$ th

(Tmin: $-2.0^{\circ} \mathrm{C}$; $\operatorname{Tmax}: 2.5^{\circ} \mathrm{C}$ ), and $1 \mathrm{st}\left(\mathrm{Tmin}:-5.6^{\circ} \mathrm{C}\right.$; Tmax: $\left.-1.0^{\circ} \mathrm{C}\right)$ percentile temperatures over the study period, respectively.

${ }^{a}$ Estimates are relative to the median temperature (Tmin: $8.3^{\circ} \mathrm{C}$; Tmax: $14.7^{\circ}$ ) and are adjusted for the pregnancies at risk and their gestational age distribution,

long-term and seasonal trends, humidity, $\mathrm{PM}_{10}, \mathrm{O}_{3}$, day of the week, holidays, and influenza epidemics. 


\section{Effect modification}

We explored potential effect modification by gestational age, gender, parity, maternal age, maternal education and degree of urbanization of maternal residence. Figure 4 presents the cumulative moderate heat effect over lag $0-1$ days estimated for different subpopulations. In addition to the heat-related increases in preterm delivery among extremely to very preterm $(<32$ weeks) and moderate to late preterm (32-36 weeks) births, we also found heat effects among early-term (37-38 weeks) and full-term (>38 weeks) births (the two latter groups not being part of the main analysis). Although confidence intervals were overlapping, there was a trend of decreasing heat effects for increasing gestational age: for minimum temperature for example, relative risks were 1.133 (95\% CI 0.920 to 1.395$), 1.078$ (95\% CI 1.015 to 1.144$), 1.050$ (95\% CI 1.019 to 1.081 ), and 1.035 (95\% CI 1.019 to 1.051$)$ for extremely to very preterm, moderate to late preterm, early-term, and full-term births, respectively. Except for a tendency of higher heat estimates for girls than for boys, there was no indication of effect modification by other variables, as confidence interval of subgroup estimates were large and the direction of differences between groups was not consistent for minimum and maximum temperature. Estimates of the cumulative moderate cold effect over lag 0-3 days did not reach significance in any of the subpopulations (figure 5).

\section{Sensitivity analysis}

Results for minimum temperature were fairly robust to changes in the maximum lag and the df for the lag-response function, the exposure-response function, the seasonal and long-term trend component, and $\log \left(W_{t}\right)$, as well as to the correction for the pregnancies at risk and their gestational age distribution: relative risk estimates ranged from 1.072 to 1.117 and from 0.992 to 1.046 for the moderate heat and cold effects, respectively (supplementary table S2). The 
exclusion of $\mathrm{O}_{3}$ from the model for minimum temperature resulted in a slight decrease of the heat effect estimate $(\mathrm{RR}=1.065,95 \% \mathrm{CI} 1.011$ to 1.122$)$. For maximum temperature (supplementary table S3), the heat effect decreased in models with fewer df for the lag-response function than in the main model, because the lag structure needs a lot of flexibility to capture the lag 1 effect. Other model changes gave similar results as the main analysis, with relative risks ranging from 1.071 to 1.100 for the heat effect and from 0.982 to 1.026 for the cold effect.

\section{DISCUSSION}

Based on data from 807,835 singleton births, we observed significant effects of recent minimum and maximum ambient temperature on the risk of preterm delivery in a temperate climate. We found an increased risk of preterm birth for high minimum temperature on the day of delivery and for low minimum temperature one to two days before delivery. Heat and cold effects of maximum temperature appeared to be delayed by one day compared to the effects of minimum temperature.

The absence of an association between maximum temperature and preterm birth on the day of delivery (lag 0) is plausible because for maximum temperature the birth precedes the exposure for a considerable number of cases. In summer, maximum temperatures can occur as late as 5 PM, whereas in winter they tend be closer to around 1 PM (Central European Time). Minimum temperatures, however, generally occur around or shortly after sunrise, so a much larger proportion of women actually experienced the lag 0 exposure before giving birth.

Although we found some indication for a cold-related increase in preterm birth few days after the exposure, cumulative cold effects were small and nonsignificant because of the seemingly protective effect of cold on the day of delivery observed for both temperature indicators. Moreover, minimum temperature showed an $\mathrm{N}$-shaped association with preterm birth, as 
increased relative risks were only observed for relatively mild low temperatures (between the 50th and the 5th percentile), but not for more extreme cold. These findings may be explained by the fact that, via clothing and heating, it is easier to adjust to low than to high temperatures. Although virtually all houses in Belgium have heating equipment, houses with air conditioning are limited.[31]

A review of the epidemiological literature on the influence of ambient temperature on birth outcomes concluded that findings for preterm delivery are inconclusive.[6] In temperate climates, a temperature-related increase in preterm birth has only been reported for Sweden,[11, 12] whereas studies on populations in Montreal, London and Germany did not find an association.[8-10] In warmer climates, effects of heat on preterm birth have been reported for Negev (Israel), California, Barcelona, Brisbane, Rome, Valencia, and China,[14-16, 27, 32-35] but not for New York and Chicago.[36, 37] Based on warm season data, Basu et al[33] found a $8.6 \%(95 \%$ CI $6.0 \%$ to $11.3 \%)$ increase in preterm birth risk for a $5.6^{\circ} \mathrm{C}$ increase in mean apparent temperature the week before delivery in California, whereas Schifano et al[15] reported an increase of $1.87 \%$ (95\% CI $0.86 \%$ to $2.87 \%$ ) for a $1^{\circ} \mathrm{C}$ increase in maximum apparent temperature (lag 0-2) in Rome. Different results for minimum and maximum temperature were reported for the warm season in Valencia[27]: compared with the median temperature, the risk of preterm birth increased up to $20 \%$ when maximum apparent temperature exceeded the 90th percentile two days before delivery and by $5 \%$ when minimum temperature rose to the 90th percentile during the 4th to 6th day before delivery. There was a trend for a negative association between preterm birth and heat exposure on the day of birth for maximum apparent temperature, but not for minimum temperature. An effect of cold on preterm birth has only been found for the historical study population (1915-1929) from Uppsala (Sweden)[11] and in a recent study from Guangzhou (China)[16]. Comparing the 1 st $\left(7.6^{\circ} \mathrm{C}\right)$ and 99th $\left(31.9^{\circ} \mathrm{C}\right)$ percentile temperatures to the median value $\left(24.4^{\circ} \mathrm{C}\right)$ in the mild climate of 
Guangzhou, the effect of cold on preterm birth $(17.9 \%$, 95\% CI $10.2 \%$ to $26.2 \%)$ was higher than the effect of heat $(10.0 \%, 95 \%$ CI $2.9 \%$ to $17.6 \%)$.[16]

We observed a trend of higher heat effects for decreasing gestational age. This is consistent with results from the Chinese study, which found that extreme heat was more strongly associated with preterm births during 20-31 and 32-34 weeks of gestation than with preterm birth during weeks 35-36.[16] Other studies, however, have reported smaller or even negative estimates for low gestational ages.[14, 15, 33] Our study suggests that high temperatures may also trigger labour among term births, and the observation of a smaller but significant heat effect for term births compared to preterm births is consistent with previous studies.[14, 33] Auger et $a l[10]$ found an association between high temperatures and the risk of delivery among term pregnancies, with higher estimates for early-term than for full-term births, but not among preterm pregnancies.

By aggregating foetuses at risk across different gestational ages, some studies ignored potential confounding caused by seasonal variations in the gestational age distribution and increasing probabilities of preterm birth with higher gestational age.[6, 28] Recent studies accounted for this issue by using a pregnancy-at-risk approach correcting for the gestational age distribution, $[9,12,27]$ or by using a time-to-event Cox proportional hazards model.[10, 11, 14, 16, 35] Studies using Cox regression estimated hazards of preterm birth associated with weekly average temperatures, which might be less appropriate to pick up very acute single-day effects as observed in our study. In the recent study from China,[16] associations based on quasiPoisson regression with DLNM were strongest for recent exposures, whereas the average temperature in the week before delivery was not associated with preterm birth in the Cox proportional hazards model. 
Temperatures for which heat-related increases in preterm birth are observed in our study are fairly mild $\left(16.3^{\circ}\right.$ for minimum temperature and $26.5^{\circ} \mathrm{C}$ for maximum temperature), but such temperatures are rather exceptional in Belgium (representing only 5\% of days). Multi-country studies on the association between temperature and mortality have shown that the unusualness of temperature rather than its absolute value determines the thresholds for health effects,[3841] indicating some adaptation to local climate. In Belgium, excess mortality is not only observed during heat waves, but also on days with maximum and minimum temperatures below $30^{\circ} \mathrm{C}$ and $20^{\circ} \mathrm{C}$, respectively.[42] In neighbouring countries (the Netherlands, Germany and the UK), estimated heat thresholds for mortality based on mean temperature range from $16.5^{\circ} \mathrm{C}$ to $22.3^{\circ} \mathrm{C} .[38,43] \mathrm{A}$ recent study[41] including a wide range of climates showed that minimum mortality in temperate regions occurs around the 80th-90th percentile of mean temperature, which is between $16.9^{\circ} \mathrm{C}$ and $19.2^{\circ} \mathrm{C}$ for our study period. Heat thresholds for non-fatal health outcomes have been studied less extensively. Significant increases in respiratory hospital admissions have been reported at fairly mild maximum apparent temperatures in NorthContinental cities such as London $\left(24.6^{\circ} \mathrm{C}\right)$ and Stockholm $\left(22.8^{\circ} \mathrm{C}\right)$.[44] Estimated mean temperature thresholds for hospital admissions for respiratory and renal diseases in Greater London were $23^{\circ} \mathrm{C}$ and $18^{\circ}$, respectively.[45]

Relative extremes of temperature are known to affect human blood flow with excess cardiovascular deaths during heat waves and cold spells. $[43,46]$ Exposure to high temperatures and dehydration reduce maternal blood flow, which may affect foetal nutrition or induce uterine contractions.[47] In addition, high ambient temperatures are associated with preeclampsia, which is a major cause of preterm birth.[5] Also the release of heat-shock proteins is linked to preterm delivery through induction of proinflammatory cytokines.[48] Furthermore, heat stress may lead to preterm delivery through an increased secretion of corticotrophin-releasing hormone and cortisol.[49] Potential biological mechanisms for an effect of low temperatures 
on preterm birth are cold-related increases in preeclampsia, pregnancy-induced hypertension, blood viscosity and vascular constriction.[11, 16]

Our study has some limitations. We used ambient temperature measurements from only one monitoring station, which may have led to exposure misclassification due to spatial variability in temperature. However, the region of Flanders is quite uniform for temperature, due to extremely small altitudinal and latitudinal gradients: elevations range from 0 to $200 \mathrm{~m}$ above sea level, and the distance between the northernmost and southernmost part is only $100 \mathrm{~km}$. Nonetheless, pregnant women may spend a lot of time indoors, where temperatures may be different because of the use of air-conditioning and/or heating. As discussed above, this may explain the absence of significant cold effects at very low temperatures. On warm days, however, outdoor temperature may be a better reflection of the true exposure because the proportion of houses equipped with air conditioning in Belgium is relatively low.[31]

The effect of temperature may differ between women with different baseline risks of premature birth. We were able to study potential effect modification by gestational age, gender, parity, maternal age, maternal education and urbanization, but we had no information on some other important risk factors for preterm birth, such as maternal comorbidity,[1] nutrition,[50] drinking[51] and smoking[52]. Maternal underweight increases the risk of spontaneous preterm birth, whereas maternal obesity is more closely linked to elective preterm delivery through obesity-related disorders such as preeclampsia and diabetes.[1, 50] Schifano et al[15] found that mothers with an obstetric pathology, eclampsia, or a chronic condition during pregnancy were less vulnerable to the effect of heat on preterm birth, which might be explained by a greater medical attention received during pregnancy by these groups of women. On the other hand, hospitalization for chronic diseases during the 2 years preceding the delivery (with cardiac disease accounting for $60 \%$ of the cases) was found to confer a greater susceptibility to 
temperature.[15] By excluding induced deliveries and caesarean sections from our study population, we limited the potential influence of pregnancy complications on our study findings. Moreover, a major strength of the time-series design is the inherent control for nontime-varying individual risk factors. Furthermore, the temporal variation and the gestational age distribution of the pregnancies at risk for preterm birth were properly accounted for in our study.

\section{CONCLUSIONS}

Our results suggest that pregnant women should protect themselves from temperature extremes. In the light of future climate projections including increases in the frequency and intensity of extreme weather events, our study may have important implications for public health, because even a mild reduction in gestational age has been linked to adverse health outcomes in early and later life.

\section{What is already known on this subject?}

Recent evidence suggests that high ambient temperatures increase the risk of preterm birth. Most of these studies were performed in warmer climates, whereas results for temperate climates are inconclusive. Moreover, only few studies have investigated the effect of cold.

\section{What this study adds?}

In a temperate European climate (Flanders, Belgium), we observed an increase in the risk of preterm birth associated with high minimum and maximum ambient temperatures. Despite the increased risk of preterm birth associated with low temperatures a few days before delivery, cumulative cold effects were small. Our results suggest that, even in a temperate climate, 
pregnant women should avoid exposure to high temperatures. In the context of climate change, these findings may have important public health implications.

\section{COMPETING INTERESTS}

The authors declare no competing interests.

\section{FUNDING}

This study was supported by the European Research Council (ERC-310898), ERA-NET FP7 ACCEPTED, and by Hasselt University Fund (BOF). The Study Centre for Perinatal Epidemiology is financed and commissioned by the Flemish Agency for Care \& Health (Agentschap Zorg en Gezondheid). Dr Gasparrini was supported by UK Medical Research Council (Grants ID: MR/M022625/1 and G1002296).

\section{CONTRIBUTORSHIP STATEMENT}

TSN and BC designed the study. BC did, with help from AVC and AG, the statistical analysis and wrote, together with TSN, the first draft of the paper. EM collected the data. All authors have contributed to the discussion and interpretation of the data, the writing of the article and approved the final version of the manuscript. 


\section{FIGURES}

Figure 1 Relative risks (RR) of preterm birth by temperature and lag days for: A) minimum temperature (Tmin); and B) maximum temperature (Tmax). Estimates are relative to the median temperature (bold lines: $8.3^{\circ} \mathrm{C}$ for $\mathrm{Tmin}$ and $14.7^{\circ}$ for Tmax) and are adjusted for the pregnancies at risk and their gestational age distribution, long-term and seasonal trends, humidity, $\mathrm{PM}_{10}, \mathrm{O}_{3}$, day of the week, holidays, and influenza epidemics.

A)

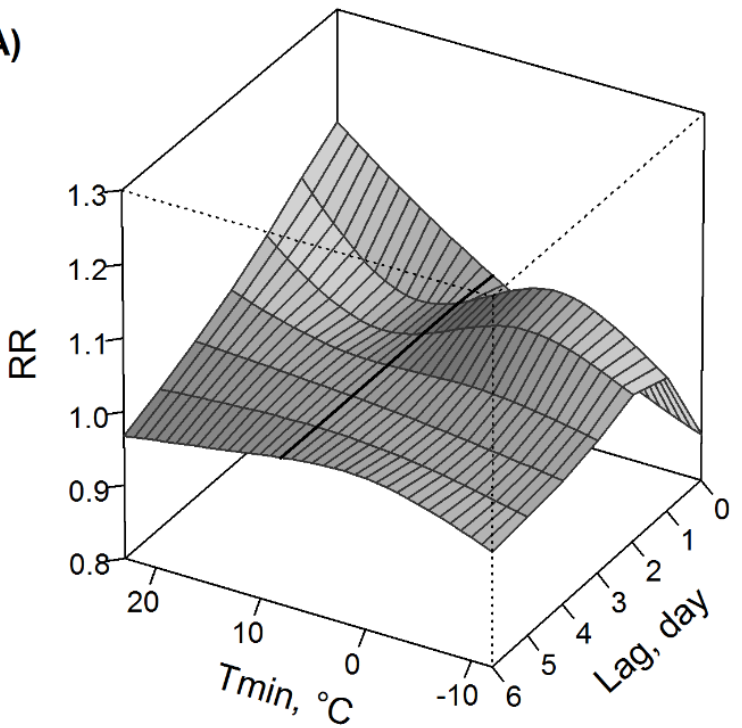

B)

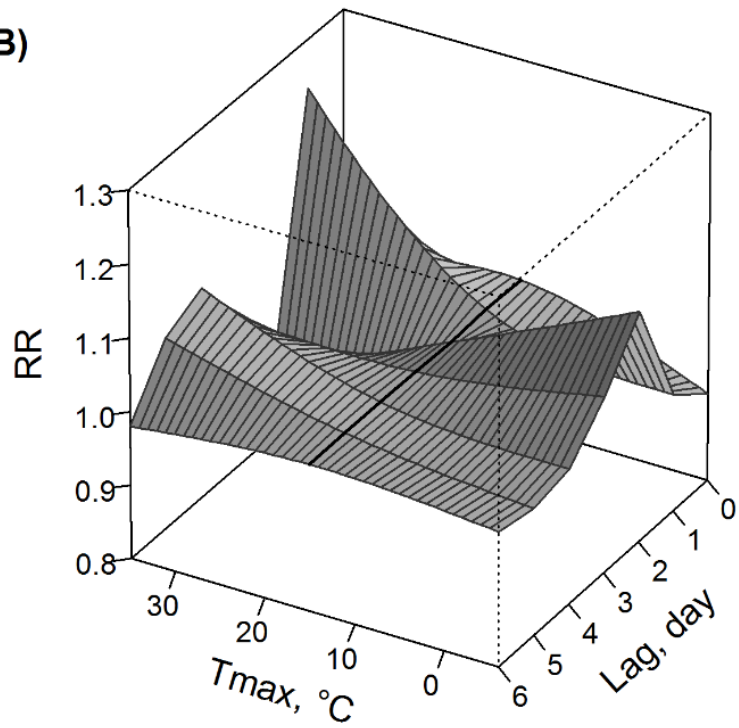


Figure 2 Lag-specific effects of minimum (Tmin) and maximum (Tmax) temperature on preterm birth estimated for: A) moderate heat; and B) moderate cold. Moderate heat and cold were defined as the 95th percentile (Tmin: $16.3^{\circ} \mathrm{C}$; Tmax: $26.5^{\circ} \mathrm{C}$ ) and the 5 th percentile (Tmin: $-2.0^{\circ} \mathrm{C}$; Tmax: $2.5^{\circ} \mathrm{C}$ ) temperatures, respectively. Estimates are relative to the median temperature (Tmin: $8.3^{\circ} \mathrm{C}$; Tmax: $14.7^{\circ}$ ) and are adjusted for the pregnancies at risk and their gestational age distribution, long-term and seasonal trends, humidity, $\mathrm{PM}_{10}, \mathrm{O}_{3}$, day of the week, holidays, and influenza epidemics. Symbols represent relative risks (RR) and error bars are $95 \%$ CIs.

A)

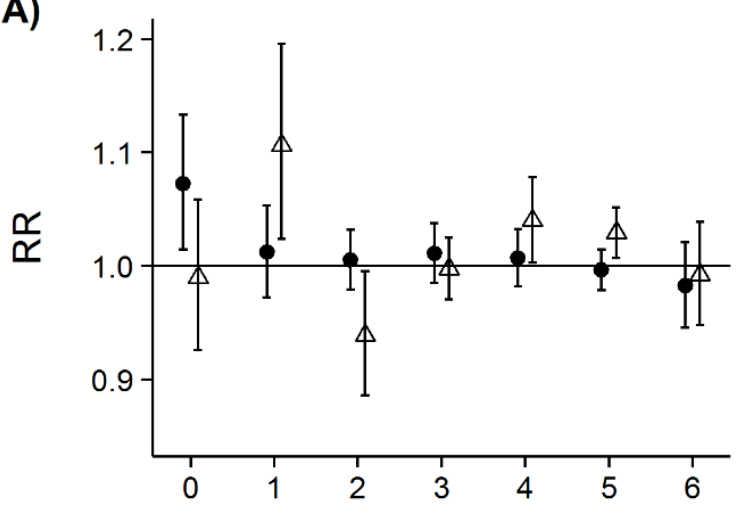

Lag, day
B)

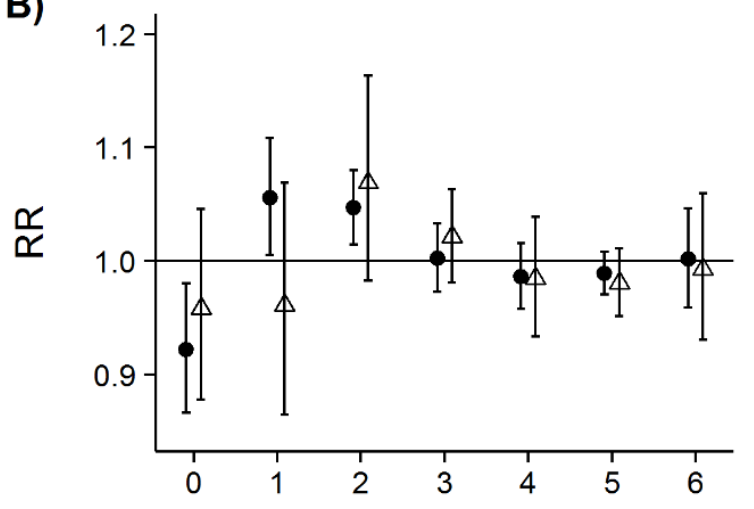

Lag, day

- $\operatorname{Tmin} \Delta \operatorname{Tmax}$ 
Figure 3 Cumulative effect of minimum (Tmin) and maximum (Tmax) temperature on preterm birth estimated over: A) lag 0-1 days; and B): lag 0-3 days. Estimates are relative to the median temperature (Tmin: $8.3^{\circ} \mathrm{C}$; Tmax: $14.7^{\circ}$ ) and are adjusted for the pregnancies at risk and their gestational age distribution, long-term and seasonal trends, humidity, $\mathrm{PM}_{10}, \mathrm{O}_{3}$, day of the week, holidays, and influenza epidemics. Lines represent the relative risks (RR), and shaded regions are $95 \%$ CIs.

A)

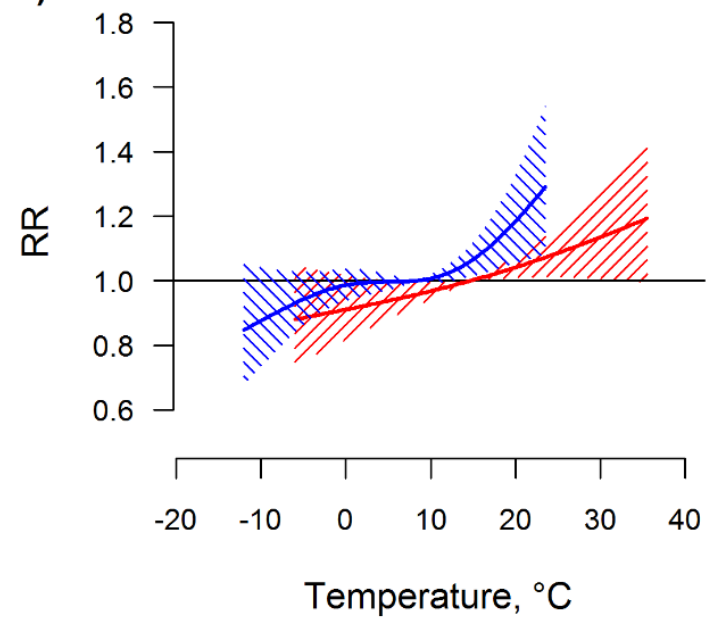

B)

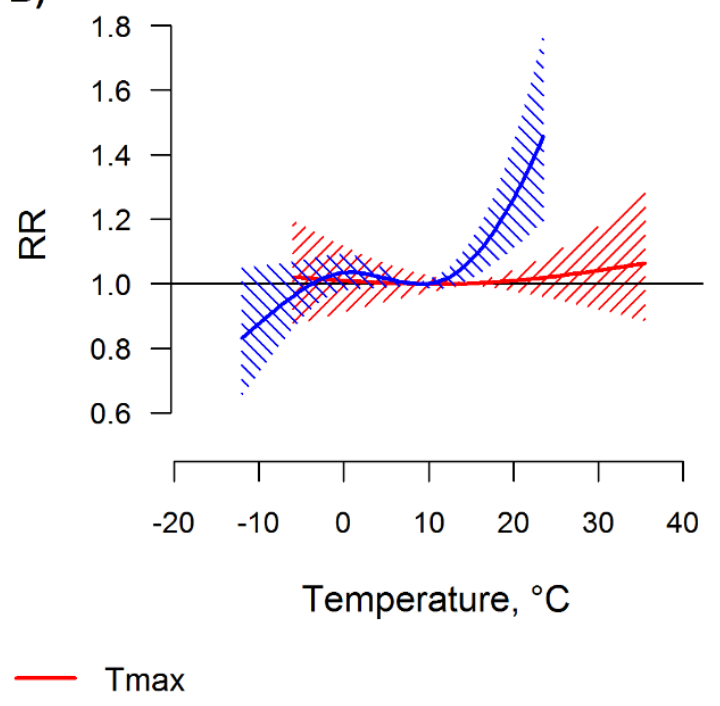


Figure 4 Cumulative moderate heat effect of minimum (Tmin) and maximum (Tmax) temperature on preterm birth over lag 0-1 days, overall and by subpopulations. Moderate heat was defined as the 95 th percentile temperature (Tmin: $16.3^{\circ} \mathrm{C}$; Tmax: $26.5^{\circ} \mathrm{C}$ ). Estimates are relative to the median temperature (Tmin: $8.3^{\circ} \mathrm{C}$; Tmax: $14.7^{\circ}$ ) and are adjusted for the pregnancies at risk and their gestational age distribution, long-term and seasonal trends, humidity, $\mathrm{PM}_{10}, \mathrm{O}_{3}$, day of the week, holidays, and influenza epidemics. *Term births (37-38 and $>38$ weeks) are not included in the main analyses (All).

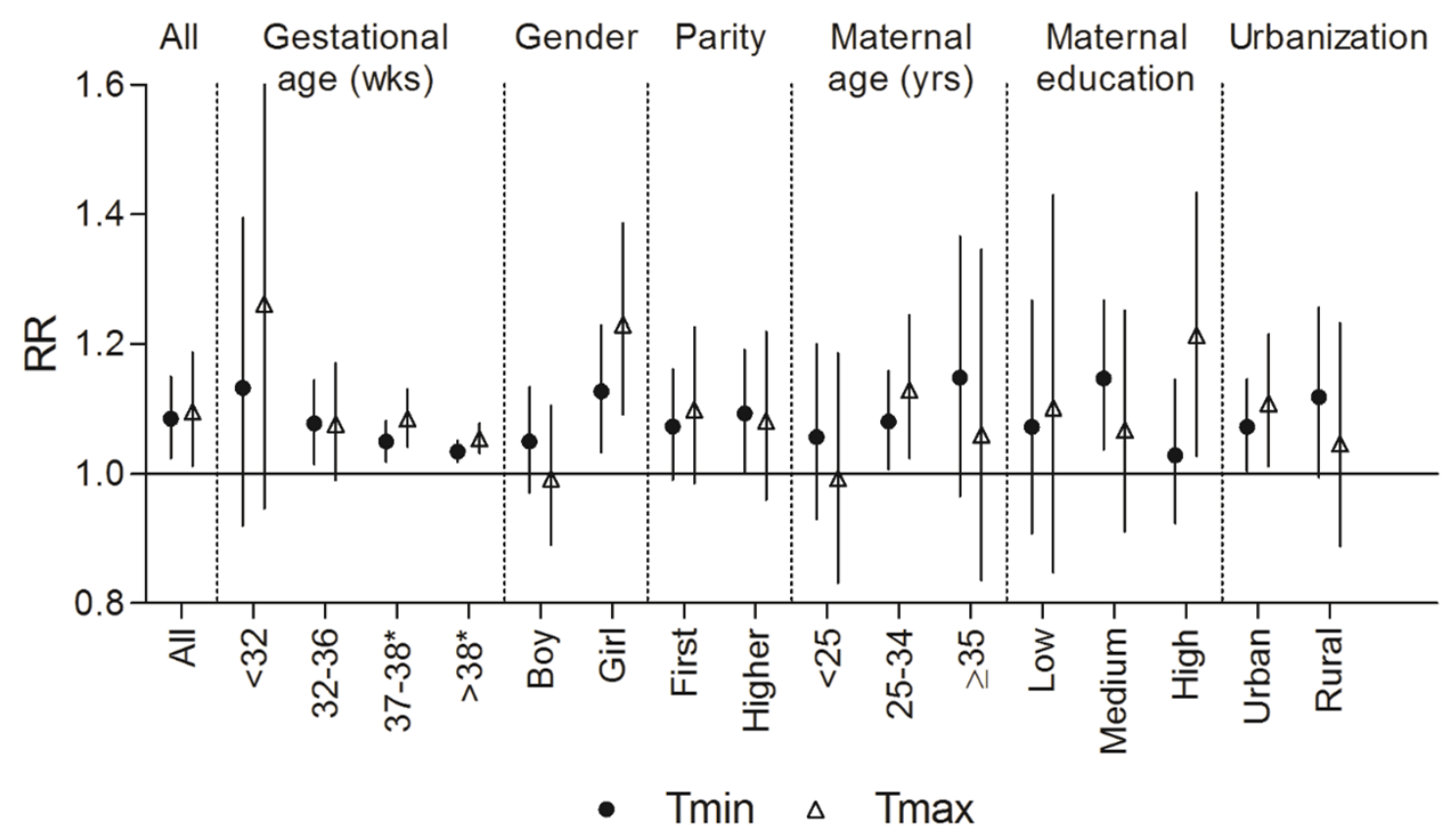


Figure 5 Cumulative moderate cold effect of minimum (Tmin) and maximum (Tmax) temperature on preterm birth over lag 0-3 days, overall and by subpopulations. Moderate cold was defined as the 5 th percentile temperature (Tmin: $-2.0^{\circ} \mathrm{C}$; Tmax: $\left.2.5^{\circ} \mathrm{C}\right)$. Estimates are relative to the median temperature (Tmin: $8.3^{\circ} \mathrm{C}$; Tmax: $14.7^{\circ}$ ) and are adjusted for the pregnancies at risk and their gestational age distribution, long-term and seasonal trends, humidity, $\mathrm{PM}_{10}, \mathrm{O}_{3}$, day of the week, holidays, and influenza epidemics. *Term births (37-38 and $>38$ weeks) are not included in the main analyses (All).

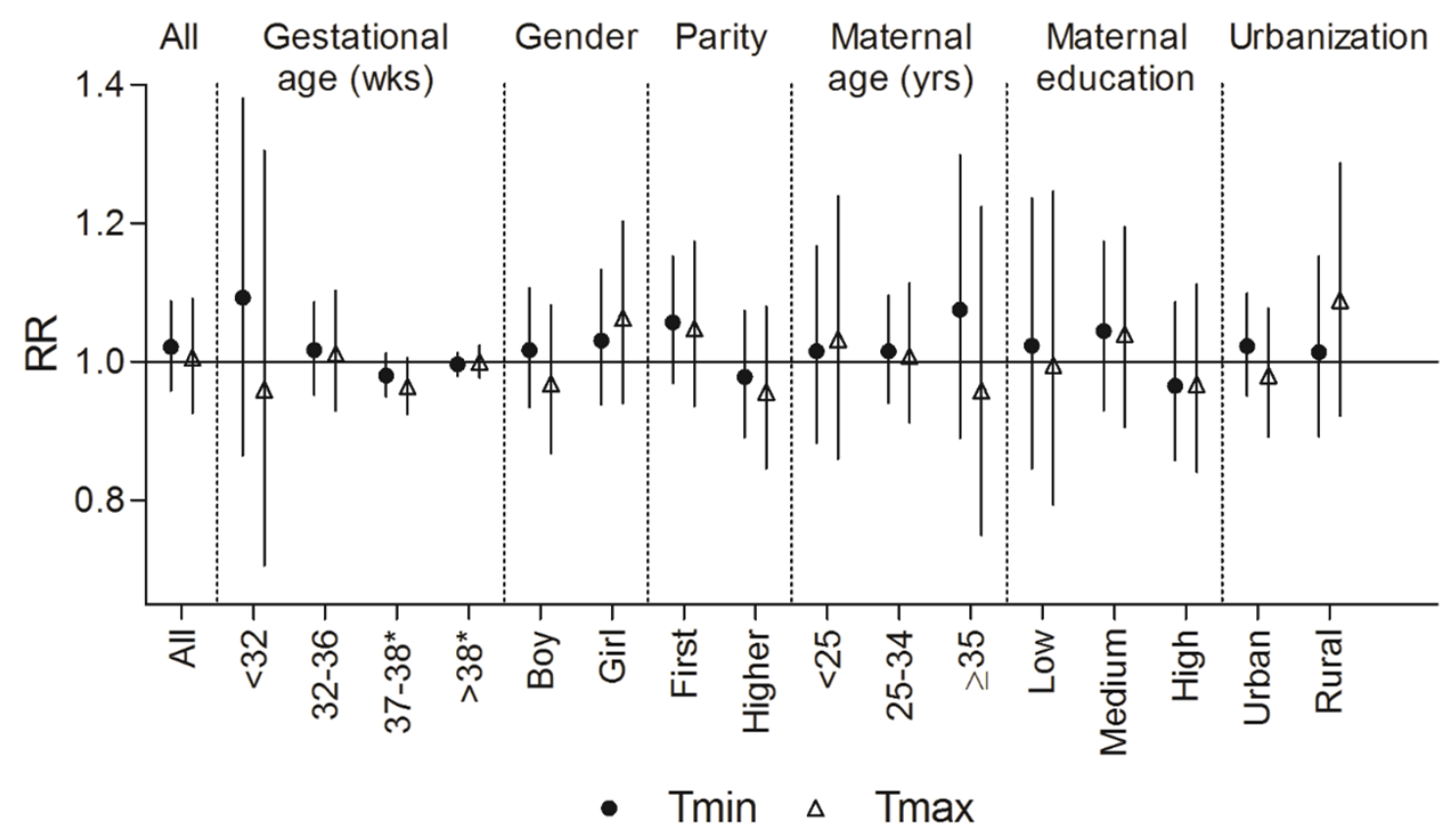




\section{REFERENCES}

1 Goldenberg RL, Culhane JF, Iams JD, et al. Epidemiology and causes of preterm birth. Lancet 2008;371:75-84.

2 Crump C, Sundquist K, Sundquist J, et al. Gestational age at birth and mortality in young adulthood. JAMA 2011;306:1233-40.

3 Mangham LJ, Petrou S, Doyle LW, et al. The cost of preterm birth throughout childhood in England and Wales. Pediatrics 2009;123:e312-27.

4 Blencowe H, Cousens S, Oestergaard MZ, et al. National, regional, and worldwide estimates of preterm birth rates in the year 2010 with time trends since 1990 for selected countries: a systematic analysis and implications. Lancet 2012;379:2162-72.

5 Institute of Medicine (US) Committee on Understanding Premature Birth and Assuring Healthy Outcomes. Preterm Birth: Causes, Consequences, and Prevention. Behrman RE, Butler AS, editors. Washington, DC: National Academies Press (US); 2007.

6 Strand LB, Barnett AG, Tong S. The influence of season and ambient temperature on birth outcomes: a review of the epidemiological literature. Environ Res 2011;111:451-62.

7 Carolan-Olah M, Frankowska D. High environmental temperature and preterm birth: a review of the evidence. Midwifery 2014;30:50-9.

8 Lee SJ, Hajat S, Steer PJ, et al. A time-series analysis of any short-term effects of meteorological and air pollution factors on preterm births in London, UK. Environ Res 2008;106:185-94.

9 Wolf J, Armstrong B. The association of season and temperature with adverse pregnancy outcome in two German states, a time-series analysis. PLoS One 2012;7:e40228.

10 Auger N, Naimi AI, Smargiassi A, et al. Extreme heat and risk of early delivery among preterm and term pregnancies. Epidemiology 2014;25:344-50. 
11 Bruckner TA, Modin B, Vagero D. Cold ambient temperature in utero and birth outcomes in Uppsala, Sweden, 1915-1929. Ann Epidemiol 2014;24:116-21.

12 Vicedo-Cabrera AM, Olsson D, Forsberg B. Exposure to seasonal temperatures during the last month of gestation and the risk of preterm birth in Stockholm. Int J Environ Res Public Health 2015;12:3962-78.

13 Lee SJ, Steer PJ, Filippi V. Seasonal patterns and preterm birth: a systematic review of the literature and an analysis in a London-based cohort. BJOG 2006;113:1280-8.

14 Strand LB, Barnett AG, Tong S. Maternal exposure to ambient temperature and the risks of preterm birth and stillbirth in Brisbane, Australia. Am J Epidemiol 2012;175:99-107.

15 Schifano P, Lallo A, Asta F, et al. Effect of ambient temperature and air pollutants on the risk of preterm birth, Rome 2001-2010. Environ Int 2013;61:77-87.

16 He JR, Liu Y, Xia XY, et al. Ambient Temperature and the Risk of Preterm Birth in Guangzhou, China (2001-2011). Environ Health Perspect 2015.

17 Keirse MJ, Hanssens M, Devlieger H. Trends in preterm births in Flanders, Belgium, from 1991 to 2002. Paediatr Perinat Epidemiol 2009;23:522-32.

18 Cammu H, Martens G, Ruyssinck G, et al. Outcome after elective labor induction in nulliparous women: a matched cohort study. Am J Obstet Gynecol 2002;186:240-4.

19 Delbaere I, Verstraelen H, Goetgeluk S, et al. Perinatal outcome of twin pregnancies in women of advanced age. Hum Reprod 2008;23:2145-50.

20 Laurent $\mathrm{O}, \mathrm{Hu} \mathrm{J}, \mathrm{Li} \mathrm{L}$, et al. A statewide nested case-control study of preterm birth and air pollution by source and composition: California, 2001-2008. Environ Health Perspect 2016.

21 Stieb DM, Chen L, Eshoul M, et al. Ambient air pollution, birth weight and preterm birth: a systematic review and meta-analysis. Environ Res 2012;117:100-11. 
22 Janssen S, Dumont G, Fierens F, et al. Spatial interpolation of air pollution measurements using CORINE land cover data. Atmos Environ 2008;42:4884-903.

23 Currie J, Schwandt H. Within-mother analysis of seasonal patterns in health at birth. Proc Natl Acad Sci U S A 2013;110:12265-70.

24 Van Casteren V, Mertens K, Antoine J, et al. Clinical surveillance of the influenza A(H1N1)2009 pandemic through the network of sentinel general practitioners. Arch Public Health 2010;68:62-7.

25 Gasparrini A, Armstrong B, Kenward MG. Distributed lag non-linear models. Stat Med 2010;29:2224-34.

26 Cox B, Martens E, Nemery B, et al. Impact of a stepwise introduction of smoke-free legislation on the rate of preterm births: analysis of routinely collected birth data. $B M J$ 2013;346:f441.

27 Vicedo-Cabrera AM, Iniguez C, Barona C, et al. Exposure to elevated temperatures and risk of preterm birth in Valencia, Spain. Environ Res 2014;134c:210-7.

28 Darrow LA, Strickland MJ, Klein M, et al. Seasonality of birth and implications for temporal studies of preterm birth. Epidemiology 2009;20:699-706.

29 Gasparrini A. Distributed lag linear and non-linear models in R: the package dlnm. J Stat Softw 2011;43:1-20.

30 Van Hecke E, Halleux JM, Decroly JM, et al. Residential and urban areas in an urbanized Belgium. Socioeconomic survey 2001 monographs [in Dutch]. Brussels, Belgium. [cited $2015 \quad$ February]. http://economie.fgov.be/nl/binaries/80325Mono\%209\%20Verstedelijking-nl-defapril_tcm325-92953.pdf.

31 Nawrot TS, Torfs R, Fierens F, et al. Stronger associations between daily mortality and fine particulate air pollution in summer than in winter: evidence from a heavily polluted region in western Europe. J Epidemiol Community Health 2007;61:146-9. 
32 Yackerson N, Piura B, Sheiner E. The influence of meteorological factors on the emergence of preterm delivery and preterm premature rupture of membrane. J Perinatol 2008;28:70711.

33 Basu R, Malig B, Ostro B. High ambient temperature and the risk of preterm delivery. Am J Epidemiol 2010;172:1108-17.

34 Dadvand P, Basagana X, Sartini C, et al. Climate extremes and the length of gestation. Environ Health Perspect 2011;119:1449-53.

35 Wang J, Williams G, Guo Y, et al. Maternal exposure to heatwave and preterm birth in Brisbane, Australia. BJOG 2013;120:1631-41.

36 Lajinian S, Hudson S, Applewhite L, et al. An association between the heat-humidity index and preterm labor and delivery: a preliminary analysis. Am J Public Health 1997;87:12057.

37 Porter KR, Thomas SD, Whitman S. The relation of gestation length to short-term heat stress. Am J Public Health 1999;89:1090-2.

38 Keatinge WR, Donaldson GC, Cordioli E, et al. Heat related mortality in warm and cold regions of Europe: observational study. BMJ 2000;321:670-3.

39 Hajat S, Kosatky T. Heat-related mortality: a review and exploration of heterogeneity. $J$ Epidemiol Community Health 2010;64:753-60.

40 Guo Y, Gasparrini A, Armstrong B, et al. Global variation in the effects of ambient temperature on mortality: a systematic evaluation. Epidemiology 2014;25:781-9.

41 Gasparrini A, Guo Y, Hashizume M, et al. Mortality risk attributable to high and low ambient temperature: a multicountry observational study. Lancet 2015;386:369-75.

42 Cox B, Wuillaume F, Van Oyen H, et al. Monitoring of all-cause mortality in Belgium (Be-MOMO): a new and automated system for the early detection and quantification of the mortality impact of public health events. Int J Public Health 2010;55:251-9. 
43 Huynen MM, Martens P, Schram D, et al. The impact of heat waves and cold spells on mortality rates in the Dutch population. Environ Health Perspect 2001;109:463-70.

44 Michelozzi P, Accetta G, De Sario M, et al. High temperature and hospitalizations for cardiovascular and respiratory causes in 12 European cities. Am J Respir Crit Care Med 2009;179:383-9.

45 Kovats RS, Hajat S, Wilkinson P. Contrasting patterns of mortality and hospital admissions during hot weather and heat waves in Greater London, UK. Occup Environ Med 2004;61:893-8.

46 Bhaskaran K, Hajat S, Haines A, et al. Short term effects of temperature on risk of myocardial infarction in England and Wales: time series regression analysis of the Myocardial Ischaemia National Audit Project (MINAP) registry. BMJ 2010;341:c3823.

47 Vaha-Eskeli K, Erkkola R. The effect of short-term heat stress on uterine contractility, fetal heart rate and fetal movements at late pregnancy. Eur J Obstet Gynecol Reprod Biol 1991;38:9-14.

48 Peltier MR. Immunology of term and preterm labor. Reprod Biol Endocrinol 2003;1:122.

49 Erickson K, Thorsen P, Chrousos G, et al. Preterm birth: associated neuroendocrine, medical, and behavioral risk factors. J Clin Endocrinol Metab 2001;86:2544-52.

50 Torloni MR, Betran AP, Daher S, et al. Maternal BMI and preterm birth: a systematic review of the literature with meta-analysis. J Matern Fetal Neonatal Med 2009;22:957-70.

51 Patra J, Bakker R, Irving H, et al. Dose-response relationship between alcohol consumption before and during pregnancy and the risks of low birthweight, preterm birth and small for gestational age (SGA)-a systematic review and meta-analyses. BJOG 2011;118:1411-21.

52 Shah NR, Bracken MB. A systematic review and meta-analysis of prospective studies on the association between maternal cigarette smoking and preterm delivery. Am J Obstet Gynecol 2000;182:465-72. 


\section{Supplementary material}

\section{Ambient temperature as trigger of preterm delivery}

\section{in a temperate climate}

Bianca Cox, Ana M Vicedo-Cabrera, Antonio Gasparrini, Harry A Roels, Evelyne Martens, Jaco Vangronsveld, Bertil Forsberg, Tim S Nawrot

\section{Table of contents}

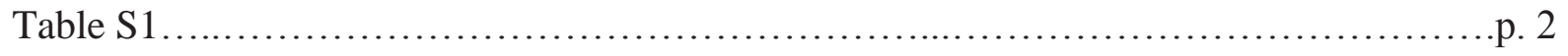

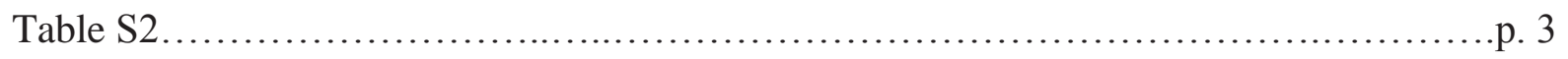

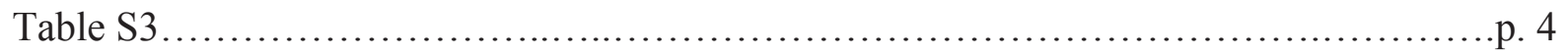


Table S1 Pearson correlation coefficients between meteorological variables and air pollutants,

Flanders, Belgium, January 1998 - July 2011

\begin{tabular}{llllll}
\hline Variable & Tmin & Tmax & Humidity & $\mathbf{P M}_{\mathbf{1 0}}$ & $\mathbf{O}_{\mathbf{3}}$ \\
\hline Tmin & 1.00 & & & & \\
Tmax & 0.90 & 1.00 & & & \\
Humidity & -0.27 & -0.52 & 1.00 & & \\
$\mathrm{PM}_{10}$ & -0.20 & -0.05 & -0.10 & 1.00 & \\
$\mathrm{O}_{3}$ & 0.52 & 0.59 & -0.58 & -0.23 & 1.00 \\
\hline
\end{tabular}

Tmin, minimum temperature; Tmax, maximum temperature; $\mathrm{PM}_{10}$, particulate matter with diameter less than $10 \mu \mathrm{m} ; \mathrm{O}_{3}$, ozone. 
Table S2 Sensitivity analysis estimates for the cumulative moderate heat and cold effects of minimum temperature on preterm birth in Flanders, Belgium, January 1998 - July 2011

\begin{tabular}{|c|c|c|c|c|}
\hline \multirow{2}{*}{ Change in main model ${ }^{\mathrm{b}}$} & \multicolumn{4}{|c|}{$\begin{array}{l}\text { Relative risks }(95 \% \mathrm{CI})^{\mathrm{a}} \\
\end{array}$} \\
\hline & \multicolumn{2}{|c|}{ Moderate heat (lag 0-1) } & \multicolumn{2}{|c|}{ Moderate cold (lag 0-3) } \\
\hline 1 & 1.085 & $(1.024$ to 1.150$)$ & 1.021 & $(0.959$ to 1.087$)$ \\
\hline \multicolumn{5}{|c|}{ Maximum lag $(l)$, days [Df for lag-response function] } \\
\hline $8[4]$ & 1.090 & $(1.029$ to 1.154$)$ & 1.029 & (0.966 to 1.097$)$ \\
\hline $8[5]$ & 1.092 & (1.027 to 1.162$)$ & 1.028 & (0.962 to 1.099$)$ \\
\hline $10[4]$ & 1.090 & (1.028 to 1.154$)$ & 1.027 & (0.964 to 1.094$)$ \\
\hline $10[5]$ & 1.089 & (1.026 to 1.155$)$ & 1.020 & (0.958 to 1.087$)$ \\
\hline \multicolumn{5}{|l|}{ Df for lag-response function } \\
\hline 3 & 1.085 & (1.024 to 1.150$)$ & 1.014 & (0.953 to 1.079$)$ \\
\hline 5 & 1.108 & (1.039 to 1.182$)$ & 1.024 & (0.958 to 1.094$)$ \\
\hline 6 & 1.117 & (1.046 to 1.192$)$ & 1.046 & (0.971 to 1.127$)$ \\
\hline \multicolumn{5}{|c|}{ Df for temperature-response function } \\
\hline 2 & 1.072 & (1.013 to 1.134$)$ & 0.992 & (0.934 to 1.053$)$ \\
\hline 4 & 1.075 & (1.013 to 1.141$)$ & 1.031 & (0.960 to 1.106$)$ \\
\hline 5 & 1.094 & (1.024 to 1.169$)$ & 1.029 & (0.958 to 1.105$)$ \\
\hline 6 & 1.089 & (1.020 to 1.163$)$ & 1.032 & (0.962 to 1.108$)$ \\
\hline \multicolumn{5}{|c|}{ Df/year for long-term and seasonal trends (time) } \\
\hline 4 & 1.076 & $(1.017$ to 1.138$)$ & 1.020 & (0.959 to 1.084$)$ \\
\hline 5 & 1.079 & (1.019 to 1.143$)$ & 1.020 & (0.959 to 1.086$)$ \\
\hline 7 & 1.088 & (1.026 to 1.153$)$ & 1.017 & (0.954 to 1.083$)$ \\
\hline 8 & 1.086 & (1.025 to 1.151$)$ & 1.011 & (0.948 to 1.078$)$ \\
\hline 9 & 1.090 & (1.028 to 1.156$)$ & 1.010 & (0.947 to 1.078$)$ \\
\hline 10 & 1.089 & (1.026 to 1.155$)$ & 1.003 & $(0.940$ to 1.071$)$ \\
\hline \multicolumn{5}{|c|}{ Df for correction gestational age distribution pregnancies at risk $\left(\log \left(W_{t}\right)\right)$} \\
\hline 1 & 1.087 & (1.026 to 1.151$)$ & 1.022 & (0.960 to 1.088$)$ \\
\hline 2 & 1.086 & (1.025 to 1.150$)$ & 1.021 & (0.959 to 1.087$)$ \\
\hline 3 & 1.085 & (1.024 to 1.150$)$ & 1.022 & (0.960 to 1.088$)$ \\
\hline 5 & 1.086 & (1.026 to 1.151$)$ & 1.021 & (0.959 to 1.087$)$ \\
\hline 6 & 1.087 & (1.026 to 1.151$)$ & 1.022 & (0.960 to 1.088$)$ \\
\hline \multicolumn{5}{|l|}{ Variable removed } \\
\hline $\mathrm{O}_{3}$ & 1.065 & (1.011 to 1.122$)$ & 1.018 & (0.958 to 1.081$)$ \\
\hline$P M_{10}$ & 1.085 & (1.027 to 1.146$)$ & 1.017 & (0.956 to 1.083$)$ \\
\hline$Z_{t}$ & 1.072 & (1.015 to 1.133$)$ & 1.022 & (0.960 to 1.088$)$ \\
\hline $\log \left(W_{t}\right)$ & 1.075 & (1.015 to 1.139$)$ & 1.025 & (0.962 to 1.091$)$ \\
\hline
\end{tabular}

Moderate heat and cold were defined as the 95 th $\left(16.3^{\circ} \mathrm{C}\right)$ and 5 th $\left(-2.0^{\circ} \mathrm{C}\right)$ percentile temperatures over the study period, respectively.

${ }^{\text {a}}$ Estimates are relative to the median temperature $\left(8.3^{\circ} \mathrm{C}\right)$.

${ }^{\mathrm{b}}$ The main DLNM model for minimum temperature has a maximum lag $(l)$ of 6 days, $4 \mathrm{df}$ for the lagresponse function, $3 \mathrm{df}$ for the temperature-response function, and is adjusted for the pregnancies at risk $\left(Z_{t}\right)$ and their gestational age distribution $\left(\log \left(W_{t}\right), 4 \mathrm{df}\right)$, long-term and seasonal trends (time, $6 \mathrm{df}$ per year), humidity ( $3 \mathrm{df})$, particulate matter $\left(P M_{10}, 3 \mathrm{df}\right)$, ozone $\left(\mathrm{O}_{3}, 3 \mathrm{df}\right)$, day of the week, holidays, and influenza epidemics. 
Table S3 Sensitivity analysis estimates for the cumulative moderate heat and cold effects of maximum temperature on preterm birth in Flanders, Belgium, January 1998 - July 2011

\begin{tabular}{|c|c|c|c|c|}
\hline \multirow{2}{*}{ Change in main model ${ }^{b}$} & \multicolumn{4}{|c|}{ Relative risk $(95 \% \mathrm{CI})^{\mathrm{a}}$} \\
\hline & \multicolumn{2}{|c|}{ Moderate heat (lag 0-1) } & \multicolumn{2}{|c|}{ Moderate cold (lag 0-3) } \\
\hline 1 & 1.096 & (1.011 to 1.187$)$ & 1.006 & (0.927 to 1.092$)$ \\
\hline \multicolumn{5}{|c|}{ Maximum lag $(l)$, days [Df for lag-response function] } \\
\hline $8[4]$ & 1.071 & $(0.993$ to 1.156$)$ & 1.017 & (0.937 to 1.105$)$ \\
\hline $8[5]$ & 1.095 & (1.010 to 1.188$)$ & 1.016 & (0.936 to 1.102$)$ \\
\hline $10[4]$ & 1.048 & (0.974 to 1.126$)$ & 1.005 & (0.931 to 1.086$)$ \\
\hline $10[5]$ & 1.087 & (1.002 to 1.180$)$ & 1.008 & $(0.913$ to 1.112$)$ \\
\hline \multicolumn{5}{|l|}{ Df for lag-response function } \\
\hline 3 & 1.037 & (0.967 to 1.113$)$ & 0.987 & $(0.915$ to 1.065$)$ \\
\hline 5 & 1.037 & (0.967 to 1.112$)$ & 0.989 & (0.916 to 1.068$)$ \\
\hline 6 & 1.093 & (1.008 to 1.186$)$ & 1.022 & (0.931 to 1.122$)$ \\
\hline \multicolumn{5}{|c|}{ Df for temperature-response function } \\
\hline 2 & 1.094 & (1.010 to 1.186$)$ & 1.007 & (0.928 to 1.092$)$ \\
\hline 4 & 1.100 & (1.009 to 1.200$)$ & 1.024 & (0.938 to 1.117$)$ \\
\hline 5 & 1.098 & (1.006 to 1.198$)$ & 1.021 & (0.934 to 1.117$)$ \\
\hline 6 & 1.100 & (1.007 to 1.201$)$ & 1.026 & (0.936 to 1.124$)$ \\
\hline \multicolumn{5}{|c|}{ Df/year for long-term and seasonal trends (time) } \\
\hline 4 & 1.093 & $(1.011$ to 1.181$)$ & 1.013 & (0.936 to 1.097$)$ \\
\hline 5 & 1.093 & (1.009 to 1.183$)$ & 1.009 & (0.930 to 1.095$)$ \\
\hline 7 & 1.094 & (1.009 to 1.186$)$ & 0.998 & (0.919 to 1.084$)$ \\
\hline 8 & 1.094 & (1.009 to 1.186$)$ & 0.989 & (0.910 to 1.076$)$ \\
\hline 9 & 1.100 & (1.014 to 1.193$)$ & 0.991 & (0.911 to 1.079$)$ \\
\hline 10 & 1.099 & (1.013 to 1.193$)$ & 0.982 & (0.903 to 1.069$)$ \\
\hline \multicolumn{5}{|c|}{ Df for correction gestational age distribution pregnancies at risk $\left(\log \left(W_{t}\right)\right)$} \\
\hline 1 & 1.097 & $(1.013$ to 1.188$)$ & 1.006 & $(0.927$ to 1.092$)$ \\
\hline 2 & 1.096 & (1.011 to 1.187 ) & 1.006 & (0.927 to 1.092$)$ \\
\hline 3 & 1.095 & (1.011 to 1.187 ) & 1.006 & (0.927 to 1.092$)$ \\
\hline 5 & 1.097 & (1.012 to 1.188$)$ & 1.006 & (0.927 to 1.092$)$ \\
\hline 6 & 1.097 & (1.013 to 1.189$)$ & 1.007 & (0.928 to 1.093$)$ \\
\hline \multicolumn{5}{|l|}{ Variable removed } \\
\hline $\mathrm{O}_{3}$ & 1.079 & (1.003 to 1.161$)$ & 0.996 & (0.920 to 1.079$)$ \\
\hline$P M_{10}$ & 1.100 & (1.021 to 1.186$)$ & 1.003 & (0.924 to 1.089$)$ \\
\hline$Z_{t}$ & 1.096 & (1.011 to 1.187 ) & 1.006 & (0.926 to 1.092$)$ \\
\hline $\log \left(W_{t}\right)$ & 1.078 & (0.995 to 1.168$)$ & 1.013 & (0.933 to 1.100$)$ \\
\hline
\end{tabular}

Moderate heat and cold were defined as the 95 th $\left(26.5^{\circ} \mathrm{C}\right)$ and 5 th $\left(2.5^{\circ} \mathrm{C}\right)$ percentile temperatures over the study period, respectively.

${ }^{a}$ Estimates are relative to the median temperature $\left(14.7^{\circ} \mathrm{C}\right)$.

${ }^{\text {b}}$ The main DLNM model for maximum temperature has a maximum lag $(l)$ of 6 days, $5 \mathrm{df}$ for the lagresponse function, $2 \mathrm{df}$ for the temperature-response function, and is adjusted for the pregnancies at risk $\left(Z_{t}\right)$ and their gestational age distribution $\left(\log \left(W_{t}\right), 4 \mathrm{df}\right)$, long-term and seasonal trends (time, $6 \mathrm{df}$ per year), humidity ( $3 \mathrm{df})$, particulate matter ( $\left.P M_{10}, 3 \mathrm{df}\right)$, ozone $\left(\mathrm{O}_{3}, 3 \mathrm{df}\right)$, day of the week, holidays, and influenza epidemics. 